\title{
Interesses Respectivos dos Acionistas Públicos e Privados nas Sociedades de Economia Mista no Brasil
}

\section{The Respective Interests of Public and Private Shareholders in Brazilian Hybrid State-Owned Enterprises}

\author{
Alexsander Dauzeley da Silva \\ Universidade de Brasília (UnB) \\ email:dauzeley@gmail.com
}

\author{
Janann Joslin Medeiros \\ Universidade de Brasília (UnB) \\ email:janmedeiros@gmail.com
}

\section{RESUMO}

As Sociedades de Economia Mista - SEM - são um tipo de organização cujo capital é constituído por recursos públicos e privados, onde o Governo é o controlador. Neste artigo, usando como marco teórico as teorias de stakeholders e institucional, investigam-se os motivos pelos quais os acionistas públicos e privados constituem e mantém capital nas SEM. Foi realizado estudo de múltiplos casos, de forma qualitativa, transversal e exploratória. Três SEM foram analisadas - Banco do Brasil, Eletrobras e Petrobras - nas quais se realizaram 28 entrevistas com pessoas chave nas organizações, além da análise de 181 artigos obtidos em mídia especializada e documentos de publicação obrigatória pelas companhias. Os dados foram compilados e codificados com o software Nvivo. Os objetivos desses stakeholders são relacionados em uma tabela. Conclui-se que estes objetivos convergem em duas lógicas institucionais distintas, porém, ambas contendo elementos rentistas e de bem-estar social.

Palavras-Chave: sociedades de economia mista; conflito de interesses de stakeholders; múltiplas lógicas institucionais; administração pública

\section{ABSTRACT}

Hybrid state-owned enterprises (SOEs) are companies whose capital is comprised of both public and private resources, with Government as the controlling shareholder. This article examines what motivates public and private investors, respectively, to invest and maintain capital in this kind of firm. Stakeholder theory and institutional theory provided the theoretical framework for conduct of this multiple case study and interpretation of its results. Hybrid SOEs analyzed in this qualitative, cross-sectional and exploratory study were Bank of Brazil, Eletrobras and Petrobras. Data - sourced from semi-structured interviews, articles published in the specialized economic media, and documents of mandatory publication made available on the respective company websites - was compiled and codified using Nvivo software. Objectives of the public and private shareholders, respectively, are identified and presented. It is concluded that these objectives are congruent with two distinct institutional logics, although both contain elements oriented to rent-seeking and to social welfare.

Key-words: hybrid state-owned enterprises; conflicting stakeholder interests; conflicting institutional logics; public administration 


\section{INTRODUÇÃO}

As Sociedades de Economia Mista - SEM - são organizações públicas de direito privado, constituídas sob a forma de sociedades anônimas de capital aberto, dividido em ações, e regidas pela legislação comum às empresas de sociedades por ações (Lei 13.303, 2016; Lei 6.404, 1976). As SEM são obrigatoriamente controladas pela administração pública direta ou indireta. Devem ser regidas pelas normas da Comissão de Valores Mobiliários - CVM, mas também devem atuar no interesse público, motivo pelo qual os objetivos devem alinhar-se com os das políticas públicas. As SEM deverão ter uma função social e devem, também, ser orientadas ao alcance do bem-estar econômico e alocação socialmente eficiente dos recursos (Lei 13.303, 2016; Lei 6.385, 1976).

Rainey, Backoff, \& Levine (1976) destacaram diferenças entre as organizações públicas e as privadas. Características das organizações públicas, das quais as SEM fazem parte, englobam maior multiplicidade de objetivos, maior tendência a conflitos de objetivos, autoridade mais fraca e fragmentada, maior cautela e rigidez, menor capacidade de inovação, maior turnover da alta administração, maior dificuldade em conceder incentivos de desempenho e eficiência aos funcionários e menor satisfação e comprometimento organizacional no trabalho (Rainey et al., 1976). Com objetivos atrelados ao cumprimento da função social e controlado pela Administração Pública, infere-se que as Sociedades de Economia Mista podem exibir as características de organizações públicas citadas por Rainey et al. (1976). No entanto, suas ações são negociadas em bolsa de valores com investidores privados, assim sendo inseridas em um contexto de organizações privadas.

As SEM fazem parte da categoria de State-Owned Enterprises - SOE. De acordo com Kowalski, Büge, Sztajerowska, \& Egeland (2013) mais de 10\% das duas mil maiores companhias do mundo são SOE, sediadas em 37 países. As SOE são responsáveis por cerca de $40 \%$ do comércio internacional e sua receita combinada produz um montante superior ao PIB de países como Inglaterra ou França (Kowalski et al., 2013). Assim, o estudo das SOE, incluindo as SEM, tem relevância tanto para a academia quanto para a gestão pública e privada.
Como SOEs, as SEM podem ainda ser classificadas como um tipo de organização híbrida. Referindo-se à distinção entre os setores econômicos público, privado e sem fins lucrativos e à premissa que categorias de organizações ostentam características que se alinham com os setores em que atuam, as organizações híbridas são descritas como formas organizacionais que se alimentam de lógicas e sistemas de valores de pelo menos duas destas categorias (Doherty, Haugh \& Lyon, 2014; Davis \& Doherty, 2019). Doherty et al. (2014) demonstraram haver espaço para avanço no arcabouço teórico e para mais debates sobre as organizações híbridas, sendo que novas interrelações no estudo das organizações híbridas continuam surgindo (Davis \& Doherty, 2019). Dessa forma, estudos sobre as SEM são de interesse também para o campo das organizações híbridas.

Uma questão fundamental em se tratar das SEM é entender as razões pelas quais investidores tanto públicos quanto privados se dispõem a colocar e manter seus recursos em SEM, já que o governo dispõe de outras formas organizacionais para cumprimento de seus propósitos, tais como as empresas totalmente estatais, enquanto os investidores privados também possuem um amplo leque de opções para investimento de capital. Neste trabalho, procura-se responder essa questão, o que pode contribuir tanto para a gestão deste tipo de organização quanto para o desenvolvimento e aprimoramento de teorias administrativas e organizacionais.

O artigo está estruturado em cinco seções, das quais esta é a primeira, sendo seguida pela fundamentação teórica, método de pesquisa, resultados e discussão e a conclusão.

\section{FUNDAMENTAÇÃO TEÓRICA}

Nesta seção, são apresentados os desenvolvimentos das teorias de stakeholders e institucional, no que dizem respeito aos interesses conflitantes de stakeholders e a pluralismo institucional e às múltiplas lógicas institucionais, respectivamente. Estudos conduzidos sob a luz de ambas as teorias não são inéditos, sendo que tal conjunção aparece, por exemplo, nos estudos de Fassin (2008) e de McCarthy, D., Puffer, S., Dunlap, D. \& Jaeger, A. (2012). 
Kraatz e Block (2008) ainda afirmam que a teoria de stakeholders incorporou progressivamente ideias da teoria institucional, citando os trabalhos de Donaldson e Preston (1995) e Mitchell, Agle e Wood (1997). Neste trabalho, conceitos das duas teorias se mostram relevantes para a compreensão das motivações que levam tanto o controlador público quanto os investidores privados a associarem-se no capital das SEM.

\subsection{Objetivos múltiplos de stakeholders}

Mitchell, Weaver, Agle, Bailey \& Carlson (2016) argumentam que as corporações podem ser conceituadas como abrangendo uma visão pluralista do que seja o bem comum. Nesse sentido, as empresas poderiam servir a propósitos e interesses múltiplos, não sendo restritas ao economic welfare (Pigou, 1962), ou à maximização da riqueza dos acionistas (Jensen \& Meckling, 1976). Jensen (2002) afirmou que, para que a tomada de decisão nas organizações seja racional, deve haver um objetivo único ao qual a organização persiga. No entanto, a teoria de stakeholders (Freeman, 1984) argumenta que as organizações estão inseridas em um contexto social, político e econômico e, portanto, precisam levar em consideração os direitos e as influências dos diversos atores deste contexto. Parte desses atores - os stakeholders - têm poder para afetar a organização ou estão sujeitos aos efeitos da existência e da ação organizacional (Freeman, 2011; Fassin, 2008; Frooman, 1999; Jones \& Wicks, 1999; Donaldson \& Preston, 1995; Freeman, 1984). Esses stakeholders podem ter objetivos diversos e, por vezes, divergentes (Bondy \& Charles, 2018; Freeman, Harrison,Wicks, Parmar \& Colle, 2010). Mitchell et al. (2016) corroboram essa ideia afirmando que os interesses diversos dos stakeholders podem se refletir, também, em múltiplos objetivos organizacionais.

A teoria de stakeholders reconhece que os stakeholders organizacionais possuem, por vezes, objetivos conflitantes entre si, e também com aqueles da própria organização onde procuram realizar esses interesses (Freeman et al., 2010; Kujala, Heikkinen \& Lehtimäki, 2012). Essa divergência de objetivos e interesses já vem sendo discutida há décadas pela academia como uma motivação subjacente para a classificação de stakeholders (Bondy \& Charles, 2018; Bowie, 1988; Fassin, 2012; 2010; 2009; 2008; Mitchell et al., 1997; Näsi, 1995) em uma tentativa de descrever e mesmo prescrever qual grupo de stakeholders a organização deve priorizar.

Em caso de conflitos entre os objetivos dos stakeholders e a incapacidade da organização em atender satisfatoriamente às demandas distintas, Bondy e Charles (2018) e Parent \& Deephouse (2007) afirmam que o poder é o principal fator considerado pela administração organizacional na gestão dessas demandas. Destaca-se que o poder é um dos vértices de uma tríade proposta por Mitchell et al. (1997) que traz também a legitimidade e a urgência como fatores de relevância na gestão dos stakeholders organizacionais. Assim, os stakeholders salientes em termos de urgência e/ou legitimidade, porém sem notório poder, seriam, por vezes, preteridos pela organização na gestão de interesses dos stakeholders desta (Bondy \& Charles, 2018).

Freeman et al. (2010) afirmam que, embora seja relativamente comum a negociação (trade-off) de interesses dos stakeholders, essa não seria a solução ideal para as situações em que haja divergência de objetivos destes atores. Caberia buscar compreender os reais interesses dos stakeholders, que podem não estar imediatamente visíveis à gestão, com o objetivo de coligá-los, produzindo ações que levem à satisfação de todos eles. No entanto, essa tarefa não é facilmente executada, demandando investimento para que seja bem-sucedida (Freeman et al., 2010).

De qualquer forma, apesar de os interesses de stakeholders serem, reconhecida e frequentemente, múltiplos nas organizações, é de interesse da organização procurar sua conciliação, seja por negociação, seja por coligação. Isso seria importante porque uma única má experiência causada na relação com um stakeholder pode ferir a reputação da empresa. Quando uma organização falha nas relações de troca com a sociedade, uma percepção de fracasso é gerada para os stakeholders envolvidos (Love \& Kraatz, 2017).

\subsection{Pluralismo institucional e pluralidade de lógicas institucionais}

Da mesma forma que a teoria de stakeholders lida com a pluralidade dos interesses dos stakeholders, a teoria institucional (Selznick, 1957) reconhece as influências do contexto na existência e na ação 
organizacional por meio das instituições sociais. Estudos posteriores nessa teoria reconheceram que um mesmo espaço social pode ser ocupado por múltiplas instituições sociais que operam de acordo com lógicas distintas, representando uma pluralidade de crenças, valores e objetivos (Besharov and Smith, 2014; Kraatz \& Block, 2008; Pache \& Santos, 2010). Friedland e Alford (1991) afirmam que:

Cada uma das mais importantes ordens institucionais das sociedades ocidentais modernas tem uma lógica central - um conjunto de práticas materiais e construções simbólicas - que constituem seus princípios organizadores e que estão disponíveis para organizações e indivíduos expandirem. A lógica institucional do capitalismo é a acumulação e comoditização da atividade humana. A do Estado é a racionalização e a regulação da atividade humana pelas hierarquias legal e burocrática. A da democracia é a participação e a extensão do controle popular sobre a atividade humana. A da família é a comunidade e a motivação da atividade humana pela lealdade incondicional aos seus membros e às suas necessidades reprodutivas. A da religião, ou da ciência, no mesmo sentido, é a verdade, seja mundana ou transcendental, e a construção simbólica da realidade na qual toda a atividade humana acontece. Essas lógicas institucionais são fundamentadas simbolicamente, estruturadas organizacionalmente, defendidas politicamente, e restritas técnica e materialmente, e por isso têm limites históricos específicos (Friedland \& Alford, 1991, tradução livre).

Thornton (2004) e Thornton, Ocasio e Lounsbury (2012) mais tarde adicionaram as profissões e as comunidades à lista das cinco instituições apresentadas por Friedland e Alford (1991).

De acordo com Mair, Mayer \& Lutz (2015, p. 713), oganizações híbridas operam em contextos de pluralidade institucional e colocam em prática elementos de lógicas institucionais múltiplas e, por vezes, conflitantes. Discorrendo sobre organizações híbridas, Pache e Santos (2010) observam que quanto mais conflituosas forem essas lógicas, maiores serão os desafios para a organização, já que frustrar ou desafiar uma ou outra demanda de uma das lógicas em conflito significa correr o risco de perdas na legitimidade da organização (Pache \& Santos, 2010). Dada a natureza híbrida das SEM inerente na forma da constituição destas por capital público e privado, considerou-se que podem existir tensões entre as demandas de seus acionistas públicos e privados decorrentes da pluralidade de lógicas institucionais nas quais as SEM estão inseridas.
Schwarzmüller, Brosi, lkens, Spörrle \& Welpe (2017) analisaram como o fluxo de investimentos em companhias de capital aberto reagiu a decisões da gestão que favoreciam um grupo de stakeholders sobre outro. O critério utilizado para caracterizar as decisões em seu estudo foi o fato de serem orientadas aos interesses dos stakeholders acionistas (investidores) ou dos não acionistas. Chamaram estes grupos, respectivamente, de rent-seeking (voltado à renda) e non-rent-seeking (não voltado à renda). Os autores não encontraram uma resposta simples para a questão da punição dos investidores a decisões que não favoreciam os acionistas. No entanto, o estudo concluiu que os investidores não aportariam recursos nas empresas quando estas simplesmente atendem os interesses dos não-acionistas, sem envidar esforços reais para contemplar às expectativas dos stakeholders cujos interesses na empresa são de natureza econômica e financeira (Schwarzmüller, et al., 2017). O estudo de Schwarzmüller et al. (2017) é relevante para a presente pesquisa não apenas por evidenciar conflitos de interesses de stakeholders em casos práticos, mas também pelo fato de ter agrupado os interesses dos stakeholders de acordo com o que poderiam ser lógicas institucionais distintas, uma voltada ao mercado e valores econômicos e outra voltada a valores e objetivos de bem-estar social (Mitchell et al., 2016). Destaca-se que Schwarzmüller et al. (2017) não utilizam a abordagem de pluralismo institucional em seu trabalho. Contudo, é possível vislumbrar na sua pesquisa a orientação dos stakeholders dos respectivos grupos por lógicas institucionais distintas.

\subsection{Lógicas institucionais nas SEM}

Aventa-se que as organizações como as SEM sejam notadamente expostas aos interesses conflitantes de stakeholders sob pelo menos duas lógicas institucionais diversas, uma representando os valores e objetivos de renda e patrimônio, ligada à instituição do mercado capitalista (Friedland \& Alford, 1991) e outra ligada a valores e objetivos não-rentistas, como o bem-estar social (Mitchell et al., 2016; Pache e Santos, 2013). As instituições que compõem o nexo no qual as SEM estão inseridas seriam ainda possivelmente mais numerosas do que uma simples díade pública-privada, conforme sugerem Thornton 
et al. (2012). Neste trabalho, porém, as lógicas institucionais nas quais as SEM operam são caracterizadas como pública e privada, pela constituição do capital dessas empresas, sendo que a lógica institucional privada diria respeito à instituição do mercado capitalista e, possivelmente, alguns dos valores relacionados às profissões representadas dentro das empresas. Já as instituições sociais que mais influenciariam a lógica institucional pública seriam o estado burocrático e a democracia, com valores voltados, principalmente, ao bem estar social (Thornton, 2004; Thornton et al., 2012).

\section{MÉTODOS}

O presente trabalho foi elaborado na base de dados levantados em pesquisa realizada para a tese de doutorado de um dos autores. No estudo original, foram selecionadas cinco SEM para comparação por meio de um estudo de casos múltiplo (Baxter \& Jack, 2008; Flick, 2014; Yin, 2015). No entanto, para os objetivos deste artigo, foram selecionadas apenas as empresas com maior semelhança de porte econômico e estrutura de capital, para aumentar a comparabilidade e o poder de conclusão da pesquisa. As empresas selecionadas para esta comparação foram o Banco do Brasil, Eletrobras e Petrobras, atuando, respectivamente, nos setores bancário, geração e distribuição de energia elétrica e produção e distribuição de petróleo e derivados.

Nestas empresas, foram entrevistadas 27 pessoas que ocuparam posições-chave na hierarquia da organização. Foram realizadas 28 entrevistas ao todo, sendo que um dos entrevistados concedeu duas entrevistas. À parte das entrevistas levantadas, também foram obtidos documentos de divulgação pública disponíveis nos respectivos sites de internet, como relatórios, balanços patrimoniais e outros documentos. Ainda, foram realizadas pesquisas em artigos divulgados pela mídia especializada, dos quais 181 foram analisados em profundidade. A seguir, encontra-se uma descrição detalhada dessas fontes.

\subsection{Entrevistas}

As entrevistas foram realizadas na modalidade semi-estruturada pois, dado o caráter exploratório da pesquisa, objetivou-se conceder razoável liberdade para os entrevistados introduzirem assuntos de potencial interesse. São reproduzidos, abaixo, algumas das questões constantes do roteiro de entrevista original, que dizem respeito aos interesses dos stakeholders investidores públicos e privados nas SEM:

\footnotetext{
- Na sua percepção, a empresa X tem uma função pública? Caso sim, qual é essa função, a seu ver?

- De que maneiras a empresa X cumpre a sua função pública?

- Na sua opinião, o que leva os acionistas da empresa X a investir na empresa?

- Que tipo(s) de retorno o investidor recebe por seu investimento na empresa?

- Quais seriam as vantagens para o investidor colocar seu dinheiro nesta empresa em vez de uma empresa privada?

- Você tem observado conflitos de interesses entre atores públicos e atores privados em nos processos decisórios da empresa? Caso sim, por favor dê alguns exemplos concretos.

- Você já esteve presente ou deliberou em uma situação em que uma demanda de natureza pública não era interessante do ponto de vista econômico/privado ou vice-versa?

(Fonte: material da pesquisa)
}

Foram entrevistadas 27 pessoas de interesse dentro das organizações, em condição de anonimato, selecionadas de maneira não-aleatória e não-amostral (Flick, 2014; Miles, Huberman \& Saldaña, 2013). A escolha foi proposital pelo domínio de função dos entrevistados. As entrevistas ocorreram entre fevereiro de 2017 e maio de 2018. À medida que as entrevistas iam sendo conduzidas, cada um dos entrevistados era convidado a sugerir outras pessoas que possuíssem conhecimento significativo do assunto em questão na organização. Essas indicações foram analisadas de acordo com sua adequabilidade para a pesquisa e, caso viáveis, as pessoas eram contatadas e convidadas a serem entrevistadas.

Se apresentam na Tabela 1 a relação de funções exercidas pelos entrevistados e o respectivo número em cada categoria. 
Tabela1: Classificação dos entrevistados por função exercida.

\begin{tabular}{l|c}
\hline \multicolumn{1}{c|}{ Função Exercida } & Quantidade Entrevistados \\
\hline Direção & 6 \\
\hline Gerência Média & 6 \\
\hline Assessoramento & 6 \\
\hline Vice-presidente & 3 \\
\hline Executivo & 2 \\
\hline Direção Ministérios & 2 \\
\hline Advogado (externo) & 2 \\
\hline Total & $\mathbf{2 7}$ \\
\hline
\end{tabular}

Fonte: dados da pesquisa.

Os entrevistados ocupam cargos ou trabalham em unidades estratégicas e táticas, ou ainda são funcionários de alto-escalão de ministérios. Foram entrevistados também dois advogados que representaram os interesses de acionistas minoritários (privados) em uma das organizações. Foram entrevistados 20 funcionários de nível estratégico e cinco em nível tático. A fase de realização de entrevistas foi encerrada no momento em que a repetição de informações de interesse começou a ocorrer com frequência, ao passo que as novas informações passaram a ser esparsas e de interesse marginal, conforme julgado por ambos os pesquisadores.

\subsection{Documentos}

Foram coletados, também, os seguintes documentos oficiais das empresas pesquisadas: instrumentos de constituição, decretos e leis, demonstrativos de resultado de exercício, balanços patrimoniais, comunicados à imprensa, comunicados de relação com investidores, publicações de fatos relevantes, releases para imprensa e outros. Os documentos foram acessados através da internet e coletados nas próprias empresas, quando disponíveis (Decreto-Lei n.900, 1969), durante o período de 2016 a 2018, na última versão disponível. Dados também foram coletados na bolsa de valores Brasil, Bolsa Balcão - B3 e em órgãos públicos como a Secretaria de Coordenação e Governança das Empresas Estatais (SEST) do Ministério do Planejamento. $\mathrm{Na}$ análise foram utilizados apenas os documentos de divulgação em caráter obrigatório das
Sociedades Anônimas e demais publicações oficiais abertas ao público. A partir desses documentos, foi possível traçar uma comparação entre as empresas pesquisadas sobre variáveis diversas, tais como porte, estrutura de capital, participação de acionistas e outras questões econômicas, concluindo-se que não haveriam maiores óbices à comparabilidade dessas organizações.

\subsection{Mídia especializada}

Bowen (2009) cita uma variedade de documentos que podem ser analisados numa pesquisa qualitativa, incluindo artigos e recortes de jornal. Afirma, ainda, que se espera do pesquisador qualitativo o uso de múltiplas - no mínimo duas - fontes de evidência. A mídia especializada escolhida foi o jornal Valor Econômico, em sua versão eletrônica, devido à disponibilidade das informações em termos transversais e longitudinais, tendo já sido utilizado como fonte em outros trabalhos científicos (ver, por exemplo, Galdi \& Gonçalves, 2018). Pontualmente, para complementação de informações, foi utilizado também um artigo do periódico especializado Isto é Dinheiro e um artigo do site de notícias G1, do grupo Globo.

Foi utilizada a ferramenta de filtragem de artigos dos sites, sendo que em um primeiro ciclo de análise (Miles et al., 2013) usou-se como filtro os próprios nomes das empresas, sendo selecionados aqueles artigos julgados a apresentar maior potencial de evidenciarem os interesses dos diversos stakeholders. No segundo ciclo, foram utilizadas palavras-chave referentes a situações específicas de divergência de interesses dos acionistas público e privados detectadas no primeiro ciclo de coleta, para selecionar os artigos submetidos a análise mais profunda. Foram selecionados 427 artigos de mídia especializada no somatório dos dois ciclos, dos quais 213, a partir da análise dos títulos, foram selecionados para leitura rápida. Foram então descartados os artigos que não apresentavam manifestação ou conflito de interesses públicos e privados dos investidores. Dos artigos selecionados para leitura rápida, 181 foram selecionados para leitura em profundidade e codificação. Neste grupo final de artigos, 62 destes estavam relacionados ao Banco do Brasil, 59 à Eletrobras e 60 à Petrobras. 


\subsection{Análise dos dados}

Das 28 entrevistas, 24 foram gravadas em áudio, sendo que três entrevistados preferiram não ter as conversas gravadas. Um entrevistado concedeu uma segunda entrevista que, por julgamento do pesquisador entrevistador, não foi gravada, na tentativa de conceder mais conforto ao entrevistado, objetivando fomentar o surgimento de mais informações relevantes. As entrevistas em áudio foram transcritas e, sobre estas transcrições, juntamente com as anotações das entrevistas que não foram gravadas em áudio, adicionadas dos artigos de mídia especializada, foi realizada análise de conteúdo utilizando codificação com as estratégias eclectic coding e holistic coding descritas por Maxwell \& Chmiel (2014) e Saldaña (2015). Os demais documentos não foram codificados pelo fato de serem essencialmente técnicos/ quantitativos e de não se tratarem dos interesses dos respectivos stakeholders, objeto do estudo. Assim, os autores julgaram de pouca relevância submetê-los à análise qualitativa.

Foram realizados dois ciclos de coleta, condensação, evidenciação e conclusões sobre os dados (Miles et al., 2013). Toda a análise de conteúdo foi operacionalizada no software Nvivo, versão 11. Foram realizados dois ciclos de codificação, sendo que o segundo tratou de refinamento e aprimoramento das informações, relações e conclusões obtidas com o primeiro ciclo (Saldaña, 2015). Como é comum em análises de conteúdo usando métodos eclectic e holisticde codificação, o primeiro ciclo teve caráter mais exploratório do que o segundo, haja vista o até-então pouco conhecimento dos pesquisadores sobre o objeto da pesquisa (Miles et al., 2013; Saldaña, 2015). No segundo ciclo, os textos já codificados foram, por vezes, revisitados em busca de significados subjacentes à luz dos novos dados e, frequentemente, agrupados sob um novo código único ou em um código inteiramente novo (Saldaña, 2015). Ambos os autores analisaram os códigos e concordaram sobre seu significado e relevância, bem como das relações entre os códigos. Não foram utilizados métodos quantitativos para estabelecer a importância destes códigos, embora a recorrência de informações tenha sido considerada como evidência da importância dos conceitos para as fontes.
O segundo ciclo de codificação gerou 32 códigos finais. As listas dos códigos criados nos dois ciclos não são aqui reproduzidas por questões de espaço. Os códigos produzidos no segundo ciclo permitiram identificar os interesses mais frequentes associados a cada tipo de investidor, sendo estes apresentados na próxima seção.

\section{RESULTADOS E DISCUSSÃO}

As empresas pesquisadas, embora atuem em segmentos diferentes, estão relativamente equiparadas em termos de porte, número de funcionários e abrangência geográfica. Todas as três apresentam ativos totais e patrimônio líquido em patamares elevados dentre as companhias nacionais. Notadamente, a participação de capital privado nestas três corporações permitiria relevância dos interesses dos investidores privados, compondo uma proporção do seu patrimônio líquido que se aproxima do máximo permitido em Lei. A legislação estabelece que os acionistas não pertencentes à administração pública tenham até metade das ações com direito a voto, menos um (Lei 13.303).

\subsection{Interesses do Controlador Público nas SEM}

A seguir, discutem-se os interesses identificados que o Governo, como acionista controlador das SEM, manifesta nestas empresas.

O primeiro desses interesses seria facilitar a implementação de políticas públicas. Como apontado nos trechos a seguir, haveria um custo maior de implantação de políticas se uma empresa totalmente privada viesse hipoteticamente a substituir uma SEM na sua função. Esse fato se dá tanto porque as SEM demandariam uma compensação menor do que as empresas privadas como porque as SEM adquiriram expertise no desempenho desse papel, com a respectiva eficiência associada (Entrevistado 4).

e... preciso fazer coisas que de repente a banca privada não quer fazer! né? OU porque não é tão rentável, OU porque não é o métier deles, né? (Entrevistado 4, BB).

[ENTREVISTADOR] o Governo poderia buscar os interesses com outro tipo de empresa, a não ser essa? [ENTREVISTADO] 
poderia, mas com mais dificuldade. Se tivesse que usar os privados, seria mais difícil. O mercado, por si só, precisa de mais controle. Por si só o mercado... O privado sempre vai procurar resultado, ativos. Teria instrumentos sim, mas com mais dificuldade (Entrevistado 3, BB).

Na primeira gestão do Lula, estava muito com essa visão de que a Petrobrás era do governo né? Então, ele tinha esse interesse mesmo de resgatar a questão, da empresa 100\% brasileira, a empresa que... a empresa que dá certo, Que vai alavancar aí o desenvolvimento do país (Entrevistado 20, Petrobras).

Tem essa questão estratégica, de interesse nacional, [...] e a questão social. Se você atinge energia elétrica em alguns municípios, você atinge não só a pessoa ficar sem luz, alimentação, coisas básicas, mas você atinge o direito da informação [...]. A educação, como que você vai se transportar, o próprio voto, [...] a democracia seria afetada também (Entrevistado 14, Eletrobras).

O Entrevistado 2, nesse sentido, também afirma que o Governo prioriza os bancos públicos quando deseja implantar uma política financeira que envolva a atuação do mercado bancário, o que pode ser a estratégia utilizada também para outras SEM quando há opção de escolha:

quando ele pensar em alguma política[...] de CRÉDITO... alguma política de Micro e Pequenas Empresas... isso aí a... a... gente vê com os olhos nisso... primeira coisa que ele chama é quem? os Bancos públicos né? (Entrevistado 2, BB)

As SEM ainda podem ter um papel de coordenação e estruturação de certas atividades estratégicas para o País. Toma-se o exemplo do BB que, embora tenha deixado, há décadas, de atuar como Banco Central e caixa do Governo (Silva \& Alperstedt, 2013), ainda teria algumas funções de estruturação do mercado atribuídas por legislação e regulamentação. O BB, na fala de vários entrevistados, teria experiência e reconhecimento dos demais atores no desempenho destes papéis. Esta ideia foi confirmada pela mídia especializada e pelos documentos levantados das empresas, que destacam seus serviços de coordenação e estruturação (Banco do Brasil, 2018). O entrevistado 11 relata atividades do $\mathrm{BB}$ que, conforme entende, seriam de difícil reprodução pelos concorrentes privados e mesmo por outros bancos públicos:

[...] hoje ele... tem papel muito importante na distribuição do... da moeda... então nós ainda temos esse papel...é... ele é preponderante no agronegócio, porque o agronegócio é um braço muito relevante da política pública... [...] o Governo ainda o tem porque é muito estratégico para o Governo. Assim, eu acho que a partir do momento que ele deixar de ser, perde completamente o sentido! né? ele ainda é um instrumento necessário para o Governo, seja nas suas políticas públicas, porque a Caixa teria dificuldade de assumi-las na totalidade.[...] a questão do SPB [sistema de pagamentos brasileiro], da compensação [de cheques entre bancos] nós ainda temos um papel muito expressivo... então nós ainda temos uma série de aspectos dentro do sistema que são coordenadas pelo Banco do Brasil. Então, ainda tem todo o sentido o Governo mantê-lo porque ele é relevante para o Governo (Entrevistado 11, BB).

[sobre a hipótese de, eventualmente, a Petrobras viesse a ser substituída por empresas privadas] De alguma maneira não vai dar certo porque, senão, uma empresa privada que fosse concorrente daria certo. [...] porque ali é um conjunto da obra, tem muita coisa envolvida [...], tem a parte do segredo, tem a gestão do conhecimento [...]. É como se fosse um relógio suiço [...], tem muita pecinha pra montar. Não, não é assim. Tanto é que aquele Eike Batista tentou fazer uma empresa de petróleo, e não conseguiu, né? [...] Então, tem alguma coisa ali, na empresa, na Petrobrás, que torna ela diferente [...] então talvez ... algumas coisas não iam mais ser feitas da maneira como são, talvez ela perdesse um pouco da criatividade que ela tem [...] (Entrevistado 16, Petrobras).

Estas atividades de coordenação seriam atribuídas às SEM por questões estratégicas para o País, como já fora evidenciado na fala do entrevistado 14, acima, além de menor nível de oposição e conflitos políticos quando em comparação com a utilização de empresas privadas. Esta realidade da também se verificou no caso da Petrobras, conforme evidenciou o Entrevistado 16.

Ainda, de acordo com os dados da pesquisa, ficou explícito que o Governo tem interesses rentistas nestas companhias. Empresas com potencial de geração de valor sustentado seriam de especial interesse como fontes de financiamento para o Tesouro Nacional, algo que pode ser importante em um cenário onde a carga tributária nacional já seja considerada elevada e aumentos de impostos para reforço do Tesouro podem ter efeitos econômicos, políticos e eleitorais negativos. Esse interesse do Governo nas SEM contrariaria uma ideia geral de que as empresas públicas se destinam exclusivamente à produção do bem público (Mitchell et al., 2016) em contraposição ao rent-seeking. No entanto, a fala do Entrevistado 10 , dentre outras, deixa claro que tal interesse existe:

O próprio Governo também deseja que retorne o capital em um nível condizente. O Governo não aceitaria, prova- 
velmente, um retorno abaixo de taxa Selic. Hoje nós estaríamos falando em um retorno de $4 \%$ ao ano. O Governo não aceita um negócio desse. Por isso que existe um esforço de os retornos estarem acima de 10 ou mais... É assim que funciona (Entrevistado 10, BB).

só pode ter essas empresas [...] eu volto insistir: ela ter resultado positivo se a... a... estrutura da governança de fato ela acontecer, dentro de parâmetros é... dentro de princípios e valores que sejam, estejam alinhados com metas e resultados, né? (Entrevistado 12, Eletrobras)

E a melhor forma da empresa contribuir para a sua função social, ela terá resultados positivos [...]. Quando você solicita para uma companhia de economia mista que ela execute funções em que você não tem um resultado semelhante que você teria se essa mesma empresa fosse de natureza privada, você está causando uma redução do valor dessa empresa (Entrevistado 27, Petrobras).

Outro interesse pouco estudado das empresas públicas seria o de servir como fonte de informações de um determinado mercado. Desta forma, uma SEM, por ter parte da sua estrutura de capital controlada por investidores privados, estaria inserida em ambientes institucionais privados dos quais o Governo, de outra forma, não obteria o mesmo nível de informações. A SEM operaria como um insider no seu mercado. O Entrevistado 6 destaca este objetivo:

por que que ... por que ter um ...? por que ter um banco?” porque... eu consigo ter uma janela [...] quer dizer: você tem um banco SEU, que pode te dar informações de como o mercado tá funcionando! (Entrevistado 6, BB).

Finalmente, foi levantado como sendo de interesse de representantes do Governo o uso das companhias públicas, incluindo-se as SEM, na busca de objetivos pessoais, políticos e/ou partidários. Isso pode advir na forma de pressões ilícitas ou antiéticas, com vistas à mobilização de recursos destinados à angariação de poder político e eleitoral ou enriquecimento pessoal. Embora este assunto tenha sido relativamente recorrente nas entrevistas realizadas, as suas causas e demais aspectos envolvidos não serão abordados em maior profundidade por não estarem no escopo deste trabalho. Os entrevistados 21 e 13, dentre outros, além de Maia (2015, outubro, 15) apontam este interesse:

As pessoas são peça-chave para esse processo, onde a corrupção ocorreria em decisões de alto-nível, sem chegar a descer para o nível técnico, e o objetivo maior seria beneficiar par- tidos políticos e suas campanhas políticas [...]. Quais seriam as motivações dos indivíduos para aceitaram a corrupção? a perpetuação no poder (Entrevistado 21, Petrobras, não gravada em áudio).

[...] indicados pelos partidos políticos [...] acabam se transformando menos em executivos e mais em braços dos próprios partidos políticos. [...] quem assina o contrato é obrigado a dar uma partilhazinha ali para o Diretor de Gestão do Contrato pra [...] levar para o partido. É pra isso que o partido indica! Não é pra fazer o melhor trabalho numa estatal! [...] Esse é um problema sério de ausência de controle [motivado por] poder e dinheiro (Entrevistado 13, Eletrobras).

[...] O programa [Destaque em Governança das Estatais] foi criado para contribuir com a "restauração da relação de confiança" entre investidores e companhias estatais. Essa relação ficou estremecida pelo cenário conturbado relacionado à Operação Lava-Jato, que investiga o esquema de cartel, corrupção e pagamento de propinas envolvendo empreiteiras, políticos e funcionários da Petrobras, e aos questionamentos sobre o respeito ao interesse público por parte das companhias. (Maia, 2015, outubro 15)

Contudo, a presença de indicados políticos nas SEM nem sempre foi reportada negativamente pelas fontes desta pesquisa. Embora estas indicações sejam geralmente recebidas desfavoravelmente pelos stakeholders investidores privados, as influências políticas por parte de partidos nas SEM também visariam obter créditos políticos e eleitorais através do direcionamento de esforços da empresa para o atendimento de pleitos de bases aliadas. O Governo, por sua vez, negociaria estes cargos como forma de obter apoio para seus projetos junto ao poder legislativo, dentre outros objetivos. Esses movimentos, apesar de criticados, estariam associados à produção do bem-estar social no sistema político brasileiro. $\mathrm{O}$ Entrevistado 10 evidencia este interesse do Governo e dos partidos nas SEM:

É a pressão dos partidos aliados da base do governo querendo ocupar um espaço [...]. Eu acho que eles querem muito para ver se conseguem influenciar em alguma coisa [em ações que beneficiem seus eleitores] que venha a influenciar a lógica do partido, parecer que está fazendo alguma coisa pelo Estado ou Município deles lá. [...] (Entrevistado $10, \mathrm{BB})$.

Ainda que não ilegais, interferências político-partidárias nas SEM geram situações de conflito com os stakeholders privados. Todavia, percebe-se uma intensificação, em anos recentes, da institucionaliza- 
ção de valores e práticas de governança privados nas empresas estatais como resposta aos abusos observados neste sentido. A Lei 13.303/2016, por exemplo, definiu notadas mudanças em termos de governança na gestão das empresas públicas, incluindo as SEM.

\subsection{Interesses dos acionistas privados nas SEM}

No levantamento dos interesses dos acionistas privados nas SEM, apresenta-se inicialomente a busca de renda, ou rent seeking (Jensen \& Meckling, 1976), como observam os entrevistados 11 e 21 , dentre outros:

O acionista ele trabalha muito em cima da expectativa de ganho e do preço de negociação e da oportunidade. [...] então, se ele enxerga ali, um preço que lhe permite ganhar, assim, isso aí é... é... muito reconhecido (Entrevistado 11, BB).

Nós temos uma assembleia de acionistas e é vendido, eu não sei quais são as bolsas, Nova York, São Paulo, [...], que são vendidas as ações [...]. Então, a gente busca esse lucro e dividir esse lucro (Entrevistado 14, Eletrobras)

Mesmo com interferência política, o acionista privado lucra muito (Entrevistado 21, Petrobras)

A fala do Entrevistado $11 \mathrm{diz}$ respeito à valorização das ações das SEM. Oportunidades de negócios com o Governo podem colocar as empresas públicas em posição de vantagem em relação às empresas privadas, o que poderia se traduzir em valorização dos papéis das SEM em bolsas de valores. Já o entrevistado 21 abordou o lucro dos acionistas no contexto dos ganhos diretos em dividendos, haja vista que as SEM foram observadas, por vezes, pagando aos acionistas um maior percentual de participação nos lucros que as empresas privadas do mesmo setor. Estes dividendos em maiores patamares seriam uma compensação pelas possíveis ineficiências das empresas resultante das interferências políticas:

[...] por que que os minoritários não saem da Eletrobrás? [...] porque no Estatuto da Eletrobrás está ASSEGURADO uma rentabilidade mínima anual [...] tá certo? está assegurado! NÃO É resultado da ação! é como se fosse, na prática, uma debênture, e não uma ação! [...] caso contrário todos já estariam fora há muito tempo! (Entrevistado 13, Eletrobras).

eu lembro que ele [um dos acionistas privados do BB] uma vez deu uma palestra pra gente ali, ele falou assim: "eu amo o Banco porque o Banco é o maior pagador de dividendo que tem!" então... ele compra as ações, sabendo que o Banco tem suas características, que o preço vai subir, mas é um bom pagador de... de dividendos. Isso quando a gente pagava $40 \%$, tá? quando a gente tinha um payout de 40 . Hoje é $25 \%$ (Entrevistado 4, BB).

As SEM também ofereceriam algumas vantagens competitivas em relação às empresas privadas, na percepção dos acionistas privados, pois o Governo teria preferência por elas na condução de projetos do próprio Governo, quando permitida por Lei. Essas informações foram trazidas pelos Entrevistados 2 e 3, não transcritas aqui por limitações de espaço.

No entanto, os acionistas privados teriam ainda outra razão para investir nas SEM, como reportam os entrevistados 11, 24 e 12:

[...] que aí é uma cultura mais perene de rendimento futuro [...] eu acho que assim, enxerga-se aqui uma fonte de resultado de longo prazo. [...] no horizonte de cinco, dez, vinte anos. Então é algo assim, pra quem espera um resultado é... a um risco menor (Entrevistado 11, BB).

[ENTREVISTADOR] O que tem na cabeça do [investidor] privado quando ele entra para participar [em uma SEM]? [ENTREVISTADO] Veja, você tem que fazer essa leitura, essa percepção, dentro de uma perspectiva mais de longo prazo (Entrevistado 24, Eletrobras).

É um mercado que sempre vai ter novos negócios, sempre vai ter novos consumidores, ou seja, então eu acho que ele acredita no longo prazo (Entrevistado 12, Eletrobras).

Esses investidores buscariam também investimentos com certo grau de rentabilidade em longo prazo, de preferência maior do que a taxa básica de juros da economia (Entrevistado 11), mas com risco reduzido em relação às empresas privadas. Esta segurança seria proporcionada pelo fato de que o principal acionista das SEM é o Governo, que é percebido como uma espécie de garantidor que, de acordo com as expectativas de ao menos parte dos investidores, não deixaria suas empresas quebrarem:

[ENTREVISTADO] ...numa empresa como essa que é estratégica, ela não morre, ela só... [é socorrida pelo governo, se transforma etc.] (Entrevistado 12, Eletrobras).

[...] mas eu acho que na verdade, em linhas gerais, a questão de governo sempre passa mais segurança. Você ter uma empresa de governo, teoricamente é uma empresa que não vai quebrar (Entrevistado 25, Petrobras). 
Uma espécie de desconto compensatório no preço das ações foi apontada pelos Entrevistados 4 e 10 no Banco do Brasil como provendo justificativa para o interesse dos investidores privados nas SEM. De maneira geral, as SEM poderiam estar realizando alocações sub ótimas de recursos em decorrência de interferências do Governo, com consequente penalização da rentabilidade para os acionistas. Assim:

[...] se fosse um racional econômico financeiro, qual seria o racional? Ao investir uma ação no Banco do Brasil, ao invés de investir no Itaú, o Banco do Brasil teria que ter um prêmio de risco maior, porque eu tenho o risco da influência de governo nele (Entrevistado 10, BB).

[ENTREVISTADOR] Por que o acionista investe na Petrobrás? [ENTREVISTADO] por questão de [...] avaliação das ações em patamar abaixo do patrimônio [...] (Entrevistado 21, Petrobras).

É interessante a percepção de que, se por um lado o governo oferece mais segurança de perenidade para as SEM, por outro, os investidores temeriam os custos decorrentes da existência de lógicas não-de-mercado nessa forma organizacional. Adachi, Mandi e Torres (2017, outubro 18), ao avaliarem a Oferta Pública de Ações - OPA - da BR Distribuidora, confirmam essa visão ao aventarem que a oferta pública de ações (OPA) da BR Distribuidora poderia não ter um grande desconto, se algum, no preço de oferta. Isso pelo fato de que a BR Distribuidora, a partir da OPA, divisava uma estrutura de comando em que os acionistas privados teriam quase igualdade de condições frente ao acionista controlador - o governo. Nas SEM, é comum que as OPA ofereçam descontos no preço das ações lançadas no mercado:

Para um investidor institucional, pelo menos à primeira vista, um conselho com $50 \%$ de integrantes independentes chega a aproximar-se, de certa forma, de um compartilhamento de controle, já que as principais decisões são feitas via conselho. Por isso não é impossível que a BR chegue a mercado com pouco ou até nenhum desconto (Adachi, Mandi \& Torres, 2017, outubro 18).

Ainda outra perspectiva de rendimento para o stakeholder investidor privado seria a possibilidade de aumento de ganhos com o incremento na eficiência das empresas. De acordo com esse racional, as SEM seriam economicamente menos eficientes do que as empresas totalmente privadas e, por isso, teriam maior possibilidade de valorização no longo prazo, em decorrência da tendência de melhoria crescente na eficiência da alocação de recursos naquelas empresas:

[...] é como se fosse uma crença que o Banco do Brasil tem de se valorizar mais no médio ou longo prazo do que o Itaú teria, porque o Itaú já está tão redondinho, enquadrado, que o preço da ação dele já está supervalorizado. [...o BB] tem potencial de crescimento, que vai melhorar, então a ação poderia se valorizar mais (Entrevistado 10, BB).

Outro interesse dos investidores privados, apontado pelas fontes, seria o de investir em empresas que teriam maior foco social e maior alinhamento com interesses do público no que tange à responsabilidade socioambiental corporativa (RSA).

\footnotetext{
O segundo que... que eu acredito que possa ser um diferencial, é as características do Banco... tem gente, pessoa física, [...] que gosta do Banco do Brasil, né? pelas características, de ser um Banco Público, né? (Entrevistado 4, BB).

Então, se o governo que esteja no momento seja mais voltado para ações sociais, ambientais, por que não investir em uma empresa que rende e ao mesmo tempo investe em questões sociais e ambientais? (Entrevistado 14, Eletrobras).
}

Em termos, os investidores privados aceitariam das SEM, até certo ponto, retornos financeiros comparativamente menores em troca de benefícios subjetivos como mitigação de certos riscos, principalmente no longo prazo, maior percepção de RSA e de aderência a valores públicos.

[...] mas eu acho que a grande maioria é uma visão de resultado estável, de longo prazo, sem grandes flutuações e não vai ganhar muito, mas vai sempre ganhar um pouquinho, um negócio legal, até porque o Governo tem o poder de fazer diferente caso ele queira (Entrevistado 25, Petrobras)

Em outras palavras: aceitar um lucro um pouco menor que uma entidade privada na mesma situação [...] (Torres, 2017, julho, 7).

\subsection{Comparação de interesses}

Na Tabela 3 se apresentam a comparação dos interesses respectivos dos investidores público e privados nas SEM. 
Tabela 3: Comparação dos interesses dos acionistas públicos e privados das SEM.

\begin{tabular}{|c|c|c|c|}
\hline $\begin{array}{l}\text { Interesses nas SEM do } \\
\text { investidor público: acionista } \\
\text { controlador (Governo, } \\
\text { Admin. Pública, Partidos } \\
\text { Políticos, Políticos) }\end{array}$ & $\begin{array}{l}\text { Lógica Institucional } \\
\text { Associada }\end{array}$ & $\begin{array}{l}\text { Interesses nas SEM dos } \\
\text { acionistas privados } \\
\text { individuais e institucionais }\end{array}$ & $\begin{array}{l}\text { Lógica Institucional } \\
\text { Associada }\end{array}$ \\
\hline $\begin{array}{l}\text { Facilitar a implementação de } \\
\text { políticas públicas }\end{array}$ & $\begin{array}{l}\text { Pública (estado burocrático - } \\
\text { bem-estar social) }\end{array}$ & Valorização das ações & $\begin{array}{l}\text { Privada (mercado capitalista - } \\
\text { acumulação) }\end{array}$ \\
\hline \multirow{2}{*}{$\begin{array}{l}\text { Obtenção de recursos para o } \\
\text { Tesouro Nacional sem aumento } \\
\text { de carga tributária }\end{array}$} & \multirow{2}{*}{$\begin{array}{l}\text { Pública (estado burocrático - } \\
\text { bem estar social, racionalização) } \\
\text { Privada (mercado capitalista - } \\
\text { acumulação) }\end{array}$} & Ganhos com dividendos & $\begin{array}{l}\text { Privada (mercado capitalista - } \\
\text { acumulação) }\end{array}$ \\
\hline & & Rentabilidade de longo prazo & $\begin{array}{l}\text { Privada (mercado capitalista - } \\
\text { acumulação) }\end{array}$ \\
\hline $\begin{array}{l}\text { Estruturação/coordenação de } \\
\text { atividades econômicas e recur- } \\
\text { sos estratégicos para o País }\end{array}$ & $\begin{array}{l}\text { Pública (estado burocrático - } \\
\text { bem-estar social) }\end{array}$ & Segurança do investimento & $\begin{array}{l}\text { Privada (mercado capitalista - } \\
\text { mitigação de riscos) }\end{array}$ \\
\hline $\begin{array}{l}\text { Fonte de informações em ativi- } \\
\text { dades econômicas de interesse } \\
\text { governamental para as políticas } \\
\text { públicas }\end{array}$ & $\begin{array}{l}\text { Pública (estado burocrático - } \\
\text { bem-estar social) }\end{array}$ & $\begin{array}{l}\text { Desconto no preço de compra } \\
\text { de ações na Bolsa por causa das } \\
\text { ineficiências presumidas por } \\
\text { causa de interferências políticas }\end{array}$ & $\begin{array}{l}\text { Privada (mercado capitalista - } \\
\text { acumulação) }\end{array}$ \\
\hline \multirow{2}{*}{$\begin{array}{l}\text { Loteamento de cargos com } \\
\text { objetivos de obter créditos e } \\
\text { vantagens para o governo em } \\
\text { negociações políticas entre os } \\
\text { poderes e com partidos }\end{array}$} & \multirow{2}{*}{$\begin{array}{l}\text { Privada (direcionamento de } \\
\text { ações para acumulação e } \\
\text { mercantilização das atividades } \\
\text { humanas, controle sobre máqui- } \\
\text { na pública com interesse público } \\
\text { ou governamental) }\end{array}$} & $\begin{array}{l}\text { Maior valor proporcional de } \\
\text { dividendos por ação e/ou divi- } \\
\text { dendos mínimos assegurados }\end{array}$ & $\begin{array}{l}\text { Privada (mercado capitalista - } \\
\text { acumulação) }\end{array}$ \\
\hline & & $\begin{array}{l}\text { Possibilidade de ganhos futuros } \\
\text { com aumento da eficiência das } \\
\text { SEM }\end{array}$ & $\begin{array}{l}\text { Privada (mercado capitalista - } \\
\text { acumulação) }\end{array}$ \\
\hline \multirow{2}{*}{$\begin{array}{l}\text { Obtenção e controle de recursos } \\
\text { por vias ilícitas ou não-éticas } \\
\text { para fins tanto lícitos quanto } \\
\text { ilícitos }\end{array}$} & \multirow{2}{*}{$\begin{array}{l}\text { Privada (direcionamento de } \\
\text { ações para acumulação e mer- } \\
\text { cantilização das atividades hu- } \\
\text { manas, controle sobre máquina } \\
\text { pública com interesse particular } \\
\text { ou partidário). }\end{array}$} & $\begin{array}{l}\text { Percepção de preferência do } \\
\text { Governo de viabilizar negócios } \\
\text { por meio das SEM }\end{array}$ & $\begin{array}{l}\text { Privada (mercado capitalista - } \\
\text { acumulação) }\end{array}$ \\
\hline & & $\begin{array}{l}\text { Percepção de maior respon- } \\
\text { sabilidade socioambiental nas } \\
\text { SEM quando comparadas com } \\
\text { empresas privadas dando maior } \\
\text { sustentabilidade à empresa }\end{array}$ & $\begin{array}{l}\text { Privada (mercado capitalista - } \\
\text { mitigação de risco); e também } \\
\text { Pública (bem-estar socioam- } \\
\text { biental) }\end{array}$ \\
\hline
\end{tabular}

Fonte: dados da pesquisa. Categorias atribuídas com base em Friedland e Alford (1991).

Por meio da análise dos interesses dos investidores público e privados resumidos na Tabela 3, percebe-se que o controlador público inclui, mas não se limita, ao governo. Nesta categoria entram também a administração pública das áreas da política pública em que a SEM se encontra, assim como partidos políticos e os próprios políticos. Os interesses desses atores nas SEM são diversos e complexos, estendendo-se desde a implementação ou promoção de políticas públicas, ao reforço do Tesouro Nacional por meio dos lucros gerados, passando por uso como moeda de troca para angariar apoio político e até a sua utilização para fins ilícitos alheios ao bem público.

Notadamente, não é possível se associar perfeitamente os interesses dos stakeholders controlador e acionistas às lógicas institucionais de mercado capitalista ou do Estado burocrático, respectivamente. Esses resultados são condizentes com teoria de stakeholders no que tange aos estudos sobre conflitos de interesses de stakeholders, ao evidenciarem que as SEM precisam lidar com uma multiplicidade de atores que detêm interesses diversos entre si e também com os das próprias organizações (Fassin, 2008; Freeman et al., 2010). Foi possível evidenciar, também, que as SEM operam em um contexto de pluralidade institucional regido por atores orientados por lógicas institucionais diferentes e, por vezes, divergentes, sendo que esse fato traria, per se, uma série de desafios à sua administração (Kraatz \& Bloock, 2008; Pache \& Santos, 2010). 
Embora as SEM tenham desafios adicionais ao lidar com lógicas institucionais plurais e conflitantes, que polarizariam seus stakeholders, foram observados alguns pontos em que os interesses do controlador público e dos acionistas privados convergem, uma possibilidade prevista por Freeman et al. (2010). Estes autores argumentam que conseguir a conjunção de interesses dos stakeholders, ao em vez de meramente procurar negociar trocas (trade-offs) entre as distintas demandas, pode permitir a criação de valor para todas as partes, embora essa criação de valor possa ter significados diferentes para lógicas institucionais distintas. Neste sentido, foi possível perceber, por exemplo, que o Estado tem eventual interesse na rentabilidade das SEM, o que permitiria reforçar seus rendimentos sem necessidade de impor novos impostos, enquanto ao menos alguns investidores privados se interessam na responsabilidade socioambiental corporativa, que pode contribuir à sobrevivência da empresa no longo prazo. Nesse último caso, as SEM podem representar mitos institucionais como sendo aquilo que é do povo... do Brasil... de todos; ou ainda aquilo que o governo vai cuidar para que não desapareça. Esse mito estaria diretamente ligado ao fato de que alguns stakeholders de lógica privada estão, até certo ponto, dispostos a realizarem um trade-off da vantagem econômica imediata pela segurança ao longo prazo, e pela percepção de que eles estariam, de alguma forma, apoiando o País ou a Nação. Mesmo investidores institucionais, como fundos de pensão ou de investimento, se confirmada a mitigação de riscos derivada da idiossincrasia estrutural das SEM, podem investir nessas empresas como forma de aumentar a segurança de suas carteiras, sem negligenciar outros motivos já citados, como o alegado maior potencial de valorização das ações. Nitidamente, nestes dois pontos de convergência citados, há oportunidades para que a gestão das SEM procure a acomodação de interesses.

Ainda, Kraatz e Block (2008) sugerem que organizações que consigam lidar satisfatoriamente com as pressões oriundas de lógicas institucionais distintas podem desenvolver uma identidade própria e durável, colaborando no processo da sua própria institucionalização. Em termos, se as SEM conseguirem sucesso ao gerenciar as tensões institucionais conflitantes, podem alcançar benefícios que não seriam possivelmente obtidos por organizações não-híbridas.

Kraatz e Block (2008) afirmam também que a característica única e mais representativa de uma organização híbrida seria a capacidade de governar a si mesma, de desenvolver uma identidade que é o foco de sua governança e alcançar estabilidade nessa prática. Então, a governança organizacional de uma SEM pode ser vista como idiossincrática, pois busca assegurar que os objetivos e os meios da aquisição destes atendam expectativas mais amplas e heterogêneas do que as de outras empresas, enfatizando a relevância da governança organizacional (Hansmann, 1996; Kraatz e Block, 2008; March \& Olsen, 1995; Williamson, 1996; Selznick, 1957). De fato, os dados levantados na pesquisa destacaram a governança como um valor notadamente desejável nas SEM, como enfatizaram Torres e Valenti (2015, jun 19), dentre outras fontes:

O escândalo da Petrobras conduziu especialistas e neófitos a uma mobilização inédita em torno de medidas que busquem melhorar a governança corporativa não apenas da petrolífera, mas de todas as estatais brasileiras (Torres \& Valenti, 2015 jun 19).

Tanto investidores privados como a própria legislação que rege as SEM têm pressionado pela institucionalização de mecanismos de governança oriundos da lógica de mercado capitalista. A Lei 13.303/2016 procurou resguardar os interesses dos investidores por vias de reforço à governança corporativa e pelo aumento do nível de accountability requerida às empresas públicas.

Finalmente, foi observado também que o Governo se mostra um stakeholder poderoso nas SEM, assumindo notada saliência quando comparado com os investidores privados. Nota-se, na listagem de interesses exibida na Tabela 3, que os objetivos do controlador público, de modo geral, se mostram mais propositivos do que se observa no caso dos privados, e que esse protagonismo estaria ligado à atuação do Governo como controlador das SEM. Nesse sentido, os investidores privados parecem figurar como convidados e sócios-minoritários das SEM, com menor poder propositivo. Mesmo assim, os stakeholders privados foram também salientes na forma de pressões por melhoria dos mecanismos de 
governança e fiscalização, com o objetivo de garantir que seus interesses sejam considerados e buscados pelas SEM. Assim, apesar de o Governo ser um stakeholder de grande poder, podendo desequilibrar à balança de interesses (Bondy \& Charles, 2018) nas SEM, mesmo os stakeholders cuja saliência se deriva da urgência e da legitimidade podem ter impacto significativo nessas organizações. Sobretudo se estes conseguirem angariar o apoio de outros stakeholders salientes - stakewatchers e stakekeepers (Fassin, 2008) como, por exemplo, a mídia, os sindicatos e os órgãos regulatórios.

\section{CONCLUSÃO}

Nesta pesquisa buscou-se compreender quais seriam os interesses dos investidores público e privados nas Sociedades de Economia Mista - SEM - no Brasil, quais as suas motivações para investir neste tipo de empresa. O Governo poderia empreender atividades econômicas por meio de companhias com capital totalmente público, enquanto os investidores privados teriam um amplo espectro de opções de investimento em companhias de capital totalmente privado. Em ambos os casos, haveria a presunção de certo grau de ônus em investir em uma empresa de natureza híbrida, devido aos conflitos nos objetivos inerentes a lógicas institucionais distintas e à necessidade de conciliação de interesses essencialmente diversos dos seus stakeholders.

A pesquisa evidenciou que as SEM operam em um contexto de pluralidade institucional regido por lógicas institucionais diversas, como preconiza a teoria institucional, onde os investidores de natureza pública, em princípio, teriam interesses mais ligados ao bem-estar social enquanto os interesses dos investidores privados seriam ligados à busca de lucros e maximização de valor econômico. No entanto, foi evidenciado que mesmo o principal acionista público pode ter interesses rentistas nas SEM, assim como acionistas privados podem se interessar pela responsabilidade socioambiental e pelo bem-estar social.

A presente pesquisa contribui às teorias de stakeholders e institucional ao evidenciar empiricamente que as SEM operam em ambiente institucional plural com stakeholders sob lógicas institucionais dis- tintas. Foi evidenciado que os interesses dos diferentes tipos de stakeholder podem convergir ou divergir, sendo que mesmo stakeholders que operam sob uma mesma lógica podem divergir em interesses entre si assim como podem alinharem-se com um ou outro interesse mais associado com uma lógica diferente.

Este trabalho também contribui para a gestão das SEM, ao evidenciar que os interesses dos acionistas destas empresas são múltiplos e complexos, e ao apontar caminhos onde estariam os pontos de convergência desses interesses. Outra contribuição é evidenciar que alguns interesses de atores públicos são alinhados à lógica de mercado, e interesses de acionistas privados podem incluir o bem-estar público. Ainda, sugere-se a necessidade de reforçar mecanismos que protejam os interesses de todos os stakeholders nas SEM, já que falhas na governança podem trazer consequências negativas para a legitimidade dessas organizações.

Limitações desta pesquisa são aquelas típicas de pesquisas qualitativas. Por exemplo, pesquisas qualitativas realizadas com análise de conteúdo estão sujeitas às limitações no conhecimento e às particularidades das percepções das fontes. Para mitigar esta limitação, foram utilizadas a variedade de fontes e a técnica de triangulação de dados. Outra possível limitação seria o número relativamente pequeno de SEM investigadas e as possíveis idiossincrasias destas, sendo que futuros estudos com a inclusão de outras empresas poderiam enriquecer a lista de interesses dos investidores nas SEM. Esta pesquisa focou um tipo específico de stakeholder: o acionista. Futuras pesquisas poderiam tratar dos interesses de um leque maior de stakeholders.

Finalmente, estudos longitudinais poderiam verificar a dinâmica dos interesses dos stakeholders ao longo do tempo. Seria de interesse, também, reproduzir este estudo em SOEs híbridas estrangeiras, para se verificar as semelhanças e diferenças entre os achados nos ambientes nacional e internacional, com possível criação de proposições teóricas generalizáveis e que avancem o poder descritivo e prescritivo das teorias envolvidas. 


\section{REFERÊNCIAS}

Adachi, V., Mandi, C., \& Torres, F. (2017, outubro 18). Temor de ingerência política pode provocar desconto no IPO da BR. Disponível em: http://www.valor.com. br/imprimir/noticia_impresso/5159676

Banco do Brasil. (2018). Sobre nós. Disponível em: http://www.bb.com.br/pbb/pagina-inicial/sobre-nos/ elbb\#/

Baxter, P. \& Jack, S. (2008). Qualitative case-study methodology: study design and implementation for novice researchers. The qualitative report, 13 (4), 544-559.

Besharov, M.L., \& Smith, W.K. (2014). Multiple Institutional Logics in Organizations: Explaining Their Varied Nature and Implications. Academy of management review, 39, 364-381.

Bondy, K., \& Charles, A. (2018). Mitigating stakeholder marginalization with the relational self. Journal of business ethics, https://doi.org/10.1007/ s10551-018-4085-x.

Bowen, G. (2009). Document analysis as a qualitative research method. Qualitative research journal, 9(2), 27-40.

Bowie, N. (1988). The moral obligations of multinational corporations. In S. Luper-Foy (Ed.), Problems of international justice: 97-113. Boulder, CO: Westview Press.

Davis, B., \& Davies, I. (2019). Balancing a hybrid business model: the search for equilibrium at Cafédirect. Journal of busines ethics, 157, 1043-1066.

Decreto-Lei n. 900, de 29 de setembro de 1969 (1969). Altera disposições do Decreto-Lei n. 200, de 25 de fevereiro de 1967, e dá outras providências. Brasília. 1969. Recuperado em 04 fevereiro, 2016, de http:// www.planalto.gov.br/ccivil_03/decreto-lei/Del0900. htm\#art5iii
Doherty, B., Haugh, E., \& Lyon, F. (2014). Social enterprises as hybrid organizations: a review and research agenda. International journal of management reviews, 16, 417-436.

Donaldson, T., \& Preston, L. (1995). The stakeholder theory of the corporation: concepts, evidence and implications. Academy of management review, 20 (1), 65-91.

Fassin, Y. (2012). Stakeholder management, reciprocity and stakeholder responsibility. Journal of business ethics, 109, 83-96.

Fassin, Y. (2010). A Dynamic Perspective in Freeman's Stakeholder Model. Journal of business ethics 96, 39. https://doi.org/10.1007/s10551-011-0942-6.

Fasin, Y. (2009). The stakeholder model refined. Journal of business ethics, 84, 113-135.

Fassin, Y. (2008). Imperfections and shortcomings of the stakeholder model's graphical representation. Journal of business ethics, 80, 879-888.

Flick, U. (2014). Mapping the field. In Flick, U. (Ed.). The Sage handbook of qualitative data analysis. Sage publications.

Freeman, R. (2011). Managing for stakeholders: trade-offs or value creation. Journal of business ethics, 96, 7-9.

Freeman, R., Harrison, J., Wicks, A., Parmar, B. \& Colle, S. (2010). Stakeholder theory: the state of the art. Cambridge University Press.

Freeman, R. (1984). Strategic management: a stakeholder approach. Cambridge University Press.

Friedland, R., \& Alford, R. (1991). Bringing society back in: symbols, practices, and institutional contradictions. In: Powel W. \& DiMaggio (eds.). The new institutionalism and organizational analysis, Univeristy of Chicago press. 
Frooman, J. (1999). Stakeholder influence strategies. Academy of management review, 24 (2), 191-205.

Galdi, F. C., \& Gonçalves, A. M. (2018). Pessimismo e incerteza das notícias e o comportamento dos investidores no Brasil. Revista de administração de empresas, 58 (2), 130-148.

Hansmann, H. (1996). The Ownership of Enterprise. Belknap Press of the Harvard University Press, Cambridge.

Jensen, M. \& Meckling, W. (1976). Theory of the firm: managerial behavior, agency costs and ownership structure. Journal of financial economics, 3, 305-360.

Jensen, M. (2002). Value Maximization, Stakeholder Theory, and the Corporate Objective Function. Business ethics quarterly, 12, 235-256. http://dx.doi. org/10.2307/3857812.

Jones T., Wicks, A. (1999). Convergent stakeholder theory. Academy of management review, 24 (2), 206-221.

Kowalski, P., Büge, M., Sztajerowska, M. \& Egeland, M. (2013). State-owned enterprises: trade effects and policy implications. OECD Trade Policy Papers, 147.

Kraatz, M., \& Block, E. (2008). Organizational implications of institutional pluralism. In R. Greenwood, C. Oliver, R. Suddaby, \& K. Sahlin (Ed.), The Sage handbook of organizational institutionalism (pp. 243-275). London: SAGE Publications Ltd.

Kujala, J., Heikkinen, A., Lehtimäki, H., (2012). Understanding the nature of stakeholder relationships: an empirical examination of a conflict situation. Journal of business ethics 109, 53-65.

Lei 13.303 (2016). Dispõe sobre o estatuto jurídico da empresa pública, da sociedade de economia mista e de suas subsidiárias, no âmbito da União, dos Estados, do Distrito Federal e dos Municípios. 30/06/2016. Acesso em: 02/12/2018. http://www.planalto.gov.br/ ccivil_03/_ato2015-2018/2016/lei/113303.htm.
Lei 6.404 (1976). Dispõe sobre as Sociedades por Ações. 15/12/1976. Acesso em: 02/12/2018. Disponível em: http://www.planalto.gov.br/ccivil_03/ LEIS/L6404consol.htm.

Lei 6.385 (1976). Dispõe sobre o mercado de valores mobiliários e cria a Comissão de Valores Mobiliários. 7/12/1976. Acesso em 02/12/2018. Disponível em: http://www.planalto.gov.br/ccivil_03/LEIS/L6385. htm.

Love, G., \& Kraatz, M. (2017). Failed stakeholder exchanges and corporate reputation: the case of earning misses. Academy of management journal, 60(3), 880-903.

Maia, C. (2015, outubro 15). Lupa nas estatais. Valor econômico. Disponível em: http://www.valor.com.br/ financas/4270092/lupa-nas-estatais\#

Mair, J., Mayer, J. \& Lutz, E. Navigating Institutional Plurality: Organizational Governance in Hybrid Organizations. Organization Studies, 36 (6): 713-739.

Maxwell, J., Chmiel, M. (2014). Notes toward a theory of qualitative data analysis. In: Flick, Uwe (Ed.). The Sage handbook of qualitative data analysis. Sage publications.

March, J., \& Olsen, J. (1998). The Institutional Dynamics of International Political Orders. International Organization, 52(4), 943-969. Retrieved August 12, 2020, from www.jstor.org/stable/2601363.

Mccarthy, D., Puffer, S., Dunlap, D., \& Jaeger, A. (2012). A Stakeholder Approach to the Ethicality of BRIC-Firm Managers' Use of Favors. Journal of business ethics. 109. 10.1007/s10551-012-1377-4.

Miles, M., Huberman, A. \& Saldanha, J. (2013). Qualitative data analysis: a method sourcebook. Sage publications.

Mitchell, R., Agle, B., \& Wood, D. (1997). Toward a theory of stakeholder identification and salience: defining the pricnple of who and what really counts. Academy of management review, 22(4), 853-886. 
Mitchell, R., Weaver, G., Agle, B., Bailey, A., \& Carlson, J. (2016). Stakeholder agency and social welfare: pluralism and decision-making in the multi-objective corporation. Academy of management review, 41(2), 252-275.

Näsi, J. (1995). What is stakeholder thinking? A snapshot of a social theory of the firm. In J. Näsi (Ed.), Understanding stakeholder thinking: 19-32. Helsinki: LSR-Julkaisut Oy.

Pache, A., \& Santos, F. (2013). Inside the hybridd organization: Selective Coupling as a Response to Competing Organizational Logics. Academy of Management Journal, 56 (4): 972-1001.

Pache, A., \& Santos, F. (2010). Inside the hybrid organization: an organizational level view of responses to conflicting institutional demands (August 2010). Research Center ESSEC Working Paper 1101, February 2011. Available at SSRN: https://ssrn.com/ abstract=2328257 or http://dx.doi.org/10.2139/ ssrn.2328257.

Parent, M., \& Deephouse, D. (2007). A case study of stakeholder identification and priorization by managers. Journal of business ethics, 75, 1-23.

Pigou, A. (1962). The economics of welfare. Macmillan.

Rainey, H., Backoff, R. \& Levine, C. (1976). Comparing public and private organizations. Public administration review, 36 (2), 233-244.

Saldaña, J. (2015). The coding manual for qualitative researchers. Sagepub.

Selznick, Philip (1957). Leadership in Administration: A Sociological Interpretation. Evanston, IL: Row, Peterson. OCLC 4800611.

Schwarzmüller, T., Brosi, P., Stelkens, V., Spörrle, M., \& Welpe, I. (2017). Investors' reactions to companies' stakeholder management: the crucial role of assumed costs and perceived sustainability. Business research, 10, 79-96.
Silva, A., \& Alperstedt, G. (2013). Mudança organizacional estratégica em um banco público: uma análise a partir da perda da conta movimento. Revista de administração pública, 47(4), 827-848.

Thornton, P., Ocasi, W., \& Lounsbury, M. (2012). The institutional logics perspective: a new approach to culture, structure, and process. Management, 15(5), 582-595.

Thornton, P. (2004). Markets from culture: institutional logics and organizational decisions in higher education publishing. Redwood, CA: Stanford University Press.

Torres, F. (2017, julho 7). Há risco de restabelecerem a 'barbárie' na gestão de estatais. Valor econômico. Disponível em: http://www.valor.com.br/imprimir/ noticia/5029794/financas/50297...

Torres, F. (2012, dezembro 3). Conflito na Eletrobras? Valor econômico / Valor investe. Disponível em: https://www.valor.com.br/valor-investe/ casa-das-caldeiras/2926634/conflito-na-eletrobras.

Torres, F., \& Valenti, G. (2015, junho 19). Governança de estatais mobiliza congresso e setor privado. Valor econômico. Disponível em: http://www.valor.com.br/ imprimir/noticia_impresso/4100544.

Williamson, O. (1996). Economics and organization: a primer. California management review, 38(2), 131-146.

Yin, R. (2015). Estudo de caso: planejamento e métodos ( $5^{\text {a }}$ ed.). Bookman. 